\title{
Vitamin $D$ deficiency and anemia risk in children: a review of emerging evidence
}

This article was published in the following Dove Press journal:

Pediatric Health, Medicine and Therapeutics

10 May 2017

Number of times this article has been viewed

\section{Samuel N Uwaezuoke ${ }^{1,2}$ \\ 'Department of Paediatrics, College of Medicine, University of Nigeria, Nsukka, ${ }^{2}$ Department of Paediatrics, University of Nigeria Teaching Hospital, Ituku-Ozalla, Nigeria}

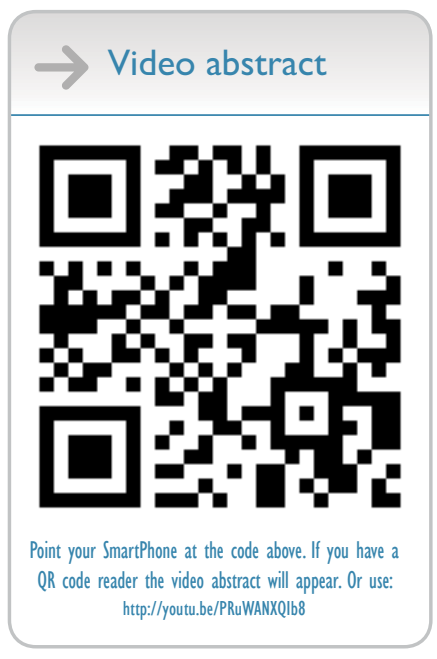

Correspondence: Samuel N Uwaezuoke Department of Pediatrics, University of Nigeria Teaching Hospital, Ituku-Ozalla, Enugu 40000I, Nigeria

Tel +2348033248108

Email snuwaezuoke@yahoo.com

\begin{abstract}
There has been renewed scientific interest in the sequelae of vitamin D deficiency, given the emerging evidence on the diverse biologic functions of vitamin $\mathrm{D}$, besides its fundamental role in bone and mineral metabolism. For the past decade, the evidence in the medical literature pointing to a relationship between anemia risk and vitamin D deficiency has been accumulating. This paper critically reviews the current evidence linking vitamin D deficiency to anemia risk in children. The synthesized evidence indicates that the studies, which were preponderantly conducted among the adult population, not only reported a bidirectional relationship between vitamin D deficiency and anemia but also showed a racial effect. In studies conducted among children, similar results were reported. Although the causal association of vitamin D deficiency with anemia risk (especially iron-deficiency anemia) remains debatable, the noncalcemic actions of the vitamin and its analogs hold prospects for several novel clinical applications. There is, however, unanimity in many reports suggesting that vitamin D deficiency is directly associated with anemia of chronic disease or inflammation. Despite the advances in unraveling the role of vitamin D in iron homeostasis, further research is still required to validate causality in the relationship between vitamin D deficiency and anemia, as well as to determine its optimal dosing, the ideal recipients for therapeutic intervention, and the preferred analogs to administer. Keywords: calcitriol deficiency, childhood anemia, iron homeostasis, causal link
\end{abstract}

\section{Introduction}

The essential physiology of vitamin D involves the sequential hydroxylation of cholecalciferol in the liver and the kidney, leading to the formation of 25-hydroxyvitamin D $(25[\mathrm{OH}] \mathrm{D})$, and $1,25(\mathrm{OH}) \mathrm{D}$, respectively, the latter being the hormonally active form of the vitamin. ${ }^{1}$ Serum $25(\mathrm{OH}) \mathrm{D}$ level is the best indicator to evaluate total vitamin D status in the body, as the metabolite is the main circulating form. ${ }^{2}$ The biologic functions of $1,25(\mathrm{OH}) \mathrm{D}$ or calcitriol are multiple, and include its classic or "calcemic" role in bone and mineral metabolism, and other nonclassic or noncalcemic actions, such as the prevention of cardiovascular disease, inhibition of renin production, prevention of specific types of malignancies, control of insulin production, modulation of immune function, and control of cellular proliferation and differentiation, because of the multiple sites of vitamin D receptors (VDRs) in the body. ${ }^{3-9}$ As such, low vitamin D status is associated with rheumatoid arthritis, inflammatory bowel diseases, multiple sclerosis, and hypertension, with proven usefulness of vitamin D supplementation or its metabolites in lowering blood pressure in hypertensive patients, improving glycemic control in type 2 diabetics, and ameliorating symptoms of rheumatoid arthritis and multiple sclerosis. ${ }^{2}$ 
Obviously, there has been renewed scientific interest in the sequelae of vitamin D deficiency, given the emerging evidence of the diverse biologic functions of vitamin $\mathrm{D}$, besides its fundamental role in bone and mineral metabolism. Several reports have also revealed the unique role of the vitamin in erythropoiesis. ${ }^{10-14}$ Specifically, vitamin D replacement has resulted in increased reticulocytosis, ${ }^{11}$ while its effects on bone marrow function and hemoglobin levels have been demonstrated. ${ }^{12,13}$

Recently, a meta-analytical study ${ }^{15}$ and several original studies $^{16-20}$ have clearly shown a bidirectional association between vitamin $\mathrm{D}$ deficiency and anemia risk in both children and adults. This relationship has brought the erythropoietic function of calcitriol to the front burner, given the effects of the vitamin on iron metabolism and the immune system. While the epidemiologic pattern of vitamin D deficiency is well established on the basis of climate and racial profile, there is generally a disparity in the prevalence of childhood anemia between developed and developing countries, eg, nutritional anemias, such as iron-deficiency anemia, are commoner in the latter. However, the anemia linked to vitamin D deficiency is essentially anemia of chronic disease or anemia of inflammation; it is the most frequent anemia in hospitalized patients globally, and is seen in patients with acute or chronic inflammatory conditions, including infections, malignancy, rheumatoid arthritis, and chronic kidney disease (CKD) ${ }^{21}$ Nevertheless, vitamin $\mathrm{D}$ deficiency has also been reported in children, adolescents, and adults with iron-deficiency anemia, although the hypothesis for its causal association is still evolving. ${ }^{22-24}$

For the past decade, the evidence in the medical literature pointing to the relationship between anemia risk and vitamin D deficiency has been accumulating. Expectedly, vitamin D may in future assume prominence in the therapeutic trajectory of children with anemia of different etiologies. This paper critically reviews the current evidence linking vitamin D deficiency to anemia risk in children.

\section{Noncalcemic actions of vitamin D}

The noncalcemic actions of vitamin D have been grouped into three major effects: control of hormone secretion, modulation of immune function, and control of cellular proliferation and differentiation. ${ }^{5}$ This classification is not clear-cut, because the effects of calcitriol on any given tissue overlap with actions from any of the three groupings. Generally, calcitriol has the following actions: it blocks parathyroid hormone (PTH) elaboration, but aids insulin secretion; it inhibits adaptive immunity, but supports innate immunity; and it hinders cell proliferation, but induces cell differentiation. ${ }^{5}$

\section{Effects of vitamin D on insulin secretion}

The association of vitamin $\mathrm{D}$ with insulin resistance or abnormal glucose metabolism has attracted scientific attention recently. With respect to insulin secretion, the stimulatory effect of calcitriol is well established, although the mechanism of action is not yet resolved. ${ }^{25,26}$ Nevertheless, a study conducted with a murine model shows that VDRs and calbindin$\mathrm{D}_{28 \mathrm{k}}$ are located in pancreatic $\beta$-cells, ${ }^{27}$ while other studies suggest that calbindin- $\mathrm{D}_{28 \mathrm{k}}$ (a calcium-buffering protein in pancreatic $\beta$-cells) not only regulates depolarization-stimulated insulin secretion ${ }^{28}$ but also protects against cytokinemediated ablation of $\beta$-cells. ${ }^{29}$ Evidence from observational human studies, ${ }^{30-32}$ and interventional human studies ${ }^{33,34}$ further indicates that vitamin D deficiency may contribute to increased risk of type 2 diabetes mellitus (T2DM).

The evolution of abnormal glucose tolerance and T2DM is usually preceded by three events: changes in the function of pancreatic $\beta$-cells, alterations in insulin sensitivity, and systemic inflammation. ${ }^{35}$ Insulin response to glucose load appears to be exclusively modulated by vitamin $\mathrm{D}$, although basal insulin is unaffected.

First, a positive role for vitamin $\mathrm{D}$ in the modification of $\beta$-cell function has been reported. ${ }^{36}$ The possible mechanisms for this role are thought to be direct stimulation of insulin secretion by vitamin D through the VDRs present in pancreatic $\beta$-cells ${ }^{36}$ and their expression of the $1 \alpha$-hydroxylase enzyme. ${ }^{37}$ In addition, calcitriol is capable of activating transcription of the gene of human insulin, and thus plays a vital role in insulin secretion. ${ }^{38}$

Second, improvement in insulin sensitivity may be mediated by vitamin $\mathrm{D}$ through direct action on the VDRs present in skeletal muscles ${ }^{39}$ and stimulation of insulin receptors expressed in bone marrow cells. ${ }^{40}$ Third, in the systemic inflammation seen in T2DM, ${ }^{41,42}$ alteration of $\beta$-cell function triggered by cell death can occur following the presence of elevated cytokines, which can also directly induce insulin resistance. Vitamin D can act to diminish systemic inflammation by its interference with elaboration and action of cytokines through retarding the role of factors responsible for nuclear transcription. ${ }^{43}$

From some of the enumerated effects of vitamin D, it is plausible to suggest that altered (reduced) insulin secretion may negatively influence erythropoiesis. For instance, a study has established that an intricate relationship exists between pancreatic cells and bone marrow-derived stem cells, as the authors were able to demonstrate the capacity of transplanted bone marrow-derived stem cells to initiate endogenous pancreatic tissue regeneration. ${ }^{44}$ 
As previously stated, insulin receptors are also expressed in bone marrow cells. Another mechanism by which reduced insulin secretion can interfere with erythropoiesis is through the inhibitory effect of cytokine-mediated systemic inflammation seen in T2DM. With regard to the relationship between altered insulin secretion and iron metabolism, other investigators have observed associations of several markers of iron metabolism with adipocyte insulin resistance and adiponectin, which suggests that factors related to iron and iron metabolism may contribute to adipocyte insulin resistance early in the pathogenesis of T2DM. ${ }^{45}$

Obviously, there appears to be a bidirectional relationship between iron metabolism and glucose homeostasis, given the fact that several pathways of iron metabolism are modulated according to systemic glucose levels, whereas insulin action and secretion are influenced by alterations in relative iron excess. ${ }^{46}$ Indeed, reduced heme synthesis and dysregulated iron uptake or export are probably contributory factors that affect glucose metabolism in old muscle cells, while iron seems to exert a modifying influence on $\beta$-cells and insulin secretion. ${ }^{46}$

In one prospective study conducted with a murine model, iron supplementation resulted in a fivefold rise in hepatic iron and serum hepcidin and a $40 \%$ elevation in fasting glucose due to insulin resistance ${ }^{47}$ Hepcidin is a peptide hormone recently identified as a key regulator of iron homeostasis and metabolism. This hormone blocks iron absorption, reduces iron release from macrophages, and releases stored iron from hepatocytes. Hepcidin is regulated by three pathways: lower iron stores, erythropoietic signals, and inflammation. Body iron deficiency induces low hepcidin synthesis, and consequently iron movement into plasma is improved. ${ }^{48}$

\section{Effects of vitamin D and other calciotropic hormones on erythropoiesis}

A recent narrative review reported several mechanistic studies, epidemiologic studies, and clinical trials that highlighted the role of vitamin $\mathrm{D}$ in iron homeostasis and erythropoiesis, and consequently its causal link with anemia. ${ }^{14}$ Vitamin D may have a positive impact on anemia (especially anemia of inflammation) through its downregulatory effects on inflammatory cytokines and hepcidin. Depressed erythropoiesis and reduced erythrocyte life span or survival is noted to be another pathophysiologic pathway that contributes to anemia of inflammation; ${ }^{49}$ the process is made possible through inflammation- and hepcidin-mediated interruptions in iron recycling, which leave inadequate iron available to support erythropoiesis. ${ }^{14}$ Furthermore, proinflammatory cytokines may depress erythropoiesis by inhibiting the elaboration of erythropoietin in the renal parenchyma, as well as the differentiation and proliferation of erythroid progenitor cells in the bone marrow. ${ }^{21}$

Vitamin D specifically enhances erythropoiesis through the following mechanisms: reduction in proinflammatory cytokines, increasing burst-forming unit-erythroid proliferation, acting in synergy with erythropoietin to promote further the proliferation of erythroid progenitor cells, ${ }^{50,51}$ and reduction in the requirements for erythropoiesis-stimulating agent (ESA) in patients with CKD. ${ }^{52,53}$ Interestingly, vitamin D and other calciotropic hormones, such as PTH and FGF23, have established effects on iron metabolism and erythropoiesis. FGF23 is synthesized in the bone but acts on FGFR1expressing kidney cells to modulate the synthesis of vitamin $\mathrm{D}$ and phosphate homeostasis. ${ }^{54}$

However, in contrast to vitamin D, FGF23 is a negative regulator of erythropoiesis and iron metabolism. Raised FGF23 levels, often associated with both cardiovascular and renal diseases, thus possess the capacity to increase anemia risk. ${ }^{55}$ Other mechanistic studies have shown that increased PTH levels may be linked with increased anemia risk through changes in erythropoiesis, which comprise reductions in erythroid progenitor formation and erythropoietin production, as well as PTH-induced fibrosis of the bone marrow. ${ }^{56}$ Despite the evidence showing that increased PTH levels may affect iron metabolism and erythropoiesis, the specific mechanisms involved and whether this relationship is independent of vitamin $\mathrm{D}$ remain unclear.

Nevertheless, some epidemiologic studies indicate that vitamin D deficiency is associated with anemia risk in children $^{57}$ and patients with $\mathrm{CKD},{ }^{58}$ while clinical trials have given disparate results on the therapeutic role of vitamin $\mathrm{D}$ in CKD-related anemia ${ }^{59-61}$ and in subjects with iron-deficiency anemia. ${ }^{62}$ For instance, the therapeutic effects of vitamin D (calcitriol) in anemia of CKD were reported as reduction in ESA requirements and elevation of hemoglobin levels, ${ }^{59,60}$ whereas a reduction in hemoglobin levels were observed in another trial. ${ }^{61}$ In the same clinical trial, ${ }^{61}$ a vitamin $\mathrm{D}$ analog (paricalcitol) was however noted to have resulted in a significant rise in hemoglobin concentration over time. Interestingly, other investigators have observed that high-dose vitamin D given in patients with iron-deficiency anemia was unlikely to give further improvements in hemoglobin concentration after correction of iron deficiency. ${ }^{62}$ These findings underscore the fact that the therapeutic effects of vitamin D may vary, depending on the cause of the anemia or the form of vitamin $\mathrm{D}$ analog used in anemic patients. 


\section{Effects of vitamin D on the immune system}

The action of vitamin D and its active metabolite (calcitriol) in the modulation of immune function was documented more than 3 decades ago. ${ }^{63-65}$ Vitamin D and CYP27B1 (a mitochondrial P450 enzyme that converts 25[OH]D to $1,25[\mathrm{OH}] \mathrm{D})$ play crucial roles in both adaptive and innate immunity. ${ }^{5}$ Apart from the proximal renal tubule, CYP27B1 is also located at other extrarenal sites such as immune cells, epithelia of many tissues, bone, and parathyroid glands. ${ }^{66}$

In adaptive immunity, $\mathrm{T}$ and $\mathrm{B}$ lymphocytes are capable of producing cytokines and immunoglobulins respectively, which target antigenic presentation by macrophages and dendritic cells. ${ }^{5}$ The inhibitory action of calcitriol on adaptive immunity involves the suppression of B-cell proliferation and immunoglobulin production, ${ }^{67}$ as well as delaying cell proliferation: especially the T-helper $\left(\mathrm{T}_{\mathrm{H}}\right)-1$ cells. ${ }^{64,68}$

On the other hand, calcitriol stimulates innate immunity through induction of expression of cathelicidin (an antimicrobial peptide) in myeloid and epithelial cells..$^{69,70}$ More importantly, vitamin D inhibits monocyte synthesis of inflammatory cytokines, such as interleukin (IL) 1, IL6, IL8, IL12, and tumor necrosis factor alpha (TNF $\alpha)$. ${ }^{71}$ Given the depressive effect of these proinflammatory cytokines on erythropoiesis, it is not surprising that vitamin D may improve erythrocyte survival and function by its inhibitory action on their production. Furthermore, calcitriol also plays a vital role in the regulation of immunity by interfering with immune-cell expression of proinflammatory cytokines, thus providing a negative feedback to circumvent excessive inflammation. ${ }^{5}$ The immunoregulatory actions of vitamin D may be key to its role in preventing anemia by means of controlling systemic cytokine release, which may in turn suppress specific inflammatory pathways contributory to the evolution of anemia. The role of inflammation in the etiology of anemia has been further clarified through the evaluation of hepcidin (an inflammation-induced negative modulator of erythropoiesis). ${ }^{72,73}$ Low levels of calcitriol have been found to be associated with elevated hepcidin levels in adult patients with CKD to buttress this finding further. ${ }^{74}$

\section{Vitamin D deficiency and anemia risk}

With the extensively documented evidence on the noncalcemic actions of vitamin D, data are also accumulating with regard to its hematologic actions, specifically its positive effect on erythropoiesis. ${ }^{10-20}$ In summary, this erythropoietic action has been attributed to the following mechanisms. First, vitamin D supplementation results in downward dose adjustments in ESA and elevated reticulocyte counts in patients undergoing hemodialysis. ${ }^{10,11}$ Second, the vitamin has been shown to influence bone marrow function, ${ }^{13}$ especially with the finding that levels of calcitriol are several hundred-fold higher in bone marrow than in plasma. ${ }^{75}$ It is speculated that vitamin D regulates the level of systemic cytokine production, thereby reducing the inflammatory milieu that results in anemia of chronic disease or inflammation. ${ }^{12}$ For instance, vitamin $\mathrm{D}$ has been found to impair cytokine release $\mathrm{e}^{75}$ and possibly exerts a direct stimulatory effect on erythroid precursors, since its receptors are also found in several nonrenal target sites, such as the bone marrow. ${ }^{13}$ Obviously, 25(OH)D deficiency leading to reduced local calcitriol production in the bone marrow may limit erythropoiesis; this observation is explained by the fact that calcitriol has a direct proliferative action on erythroid burst-forming units (in synergy with the activity of endogenously produced erythropoietin) and also upregulates expression of the erythropoietin receptor on erythroid progenitor cells. . $^{11,51,76}$

Therefore, the various noncalcemic actions of vitamin D appear to revolve around the improvement of anemia. Remarkably, several population-based studies have shown that the relationship between vitamin $\mathrm{D}$ and anemia risk may however differ with respect to the etiology of anemia, ${ }^{16,23}$ as well as the racial profile of the subjects. ${ }^{16,77-79}$

\section{Anemia related to micronutrient deficiency (nutritional anemia)}

The association of vitamin D with iron-deficiency anemia has been well reported. ${ }^{16,23,62}$ In a recently published crosssectional study conducted among 10,410 children and adolescents aged 1-21 years, Atkinson et al evaluated the relationship between $25(\mathrm{OH}) \mathrm{D}$ deficiency and anemia in a cohort of otherwise-healthy children, and also determined whether race was a modifying factor in this association. ${ }^{16}$ The results of their study suggested that $25(\mathrm{OH}) \mathrm{D}$ deficiency was associated with increased risk of anemia in healthy children, but 25(OH)D-threshold levels for lower hemoglobin were lower in black children than white children. Notably, the observed association between vitamin D status and anemia was independent of other confounding factors that could have contributed to anemia risk, namely, obesity, inflammation, socioeconomic status, and nutritional status, including vitamin $\mathrm{B}_{12}$, folic acid, and iron deficiencies. ${ }^{16}$

The authors documented these study weaknesses: its cross-sectional nature, which precluded conclusive evidence on causality in the association between vitamin D deficiency 
and lower hemoglobin levels, lack of access to data on iron deficiency (one of the most common etiologies of anemia in children), and lack of access to data to estimate the prevalence of hereditary hemoglobinopathies (which may be associated with lower hemoglobin levels, particularly in black children). Since there was a lack of evidence about the iron-deficiency status of the subjects used in this study, it is plausible that the mechanistic relationship between vitamin $\mathrm{D}$ deficiency and anemia may be predicated upon its negative stimulatory effect on the bone marrow.

Worse still, the nonconsideration of other confounders, including vitamin $\mathrm{B}_{12}$ and folate deficiencies, suggests that vitamin D deficiency may not have played a causal role in the relationship with anemia, but could have been an effect or outcome of the anemic state in these subjects. Furthermore, the previously noted observation that high-dose vitamin $\mathrm{D}$ given to patients with iron-deficiency anemia failed to increase hemoglobin concentration after correction of iron deficiency ${ }^{62}$ also lends credence to the view that vitamin $\mathrm{D}$ deficiency may not be a contributor to anemia in irondeficiency anemia.

For instance, there is evidence pointing to a possible relationship between vitamin D deficiency and osteoporosis in iron-deficient patients, while alterations in vitamin D metabolism may arise from iron deficiency itself. ${ }^{81}$ This is because iron is crucial for vitamin D metabolism, as all of the vitamin D-related cytochromes catalyze single- or multiplehydroxylation reactions on specific carbons of the vitamin D substrate by utilizing heme-bound iron. ${ }^{81}$

Interestingly, there are now more data to support the hypothesis that chronic iron deficiency with or without anemia is indeed associated with bone loss and osteoporosis. ${ }^{82}$ The suggested mechanisms to explain this relationship between iron deficiency and bone loss include interference with collagen synthesis, in which iron plays a vital role, alterations in vitamin $\mathrm{D}$ metabolism, as previously mentioned, and anemia-induced hypoxia, which is a major stimulator of bone resorption. ${ }^{82}$ One study has confirmed that iron-deficiency anemia had a significant impact upon the bone, specifically affecting bone mineralization, decreasing matrix formation, and increasing bone resorption. ${ }^{83}$ Another intriguing report indicated that the prevalence of vitamin D deficiency or insufficiency was very high in an iron-deficient state. In addition, it appears the recovery of iron status does not affect $25(\mathrm{OH}) \mathrm{D}$ levels, but the increase in iron supply to the tissues is lower if vitamin D deficiency is also present. ${ }^{84}$

It is important at this juncture to highlight other studies on the relationship between vitamin D deficiency and anemia (Table 1). In a cross-sectional study of 554 subjects aged above 17 years, Sim et al evaluated the prevalence of anemia in those with vitamin D deficiency in comparison with those who had normal levels of the vitamin. ${ }^{12}$ They reported a statistically significant difference between the prevalence of anemia in $25(\mathrm{OH}) \mathrm{D}$-deficient subjects and its prevalence in those with normal $25(\mathrm{OH}) \mathrm{D}$ levels. In addition, $25(\mathrm{OH})$ D-deficient subjects had lower mean hemoglobin and more prevalent use of ESA. Sim et al's findings underscored a possible correlation between vitamin D deficiency and anemia, but again failed to establish a causal association. The study had several confounding factors, namely, evidence of prevalent malnutrition and inflammation in $25(\mathrm{OH}) \mathrm{D}$-deficient subjects, selection bias due to the observational nature of the study, inadequate exposure to sunlight among study cohorts, exclusion of common etiologies of anemia, such as iron, vitamin $\mathrm{B}_{12}$, and folic acid deficiencies, and estimation of concurrent 25(OH)D and hemoglobin levels within 6 months of each other in the study. ${ }^{12}$ Nevertheless, the study appears to be among the pioneer work to investigate the relationship between vitamin $\mathrm{D}$ and anemia by enrolling subjects without CKD and/or not on ESA.

In another study conducted among hospitalized adult patients in France, Coutard et al aimed to investigate the rela-

Table I Overview of studies on relationship between vitamin D deficiency and anemia

\begin{tabular}{lllll}
\hline Study & Design & Sample size & Age range & $\begin{array}{c}\text { Anemia/vitamin D-deficiency } \\
\text { risk, OR (95\% Cl) }\end{array}$ \\
\hline Atkinson et al, ${ }^{16}$ USA & Cross-sectional & 10,410 & $1-12$ years & $1.47(1.14-1.89)^{*, \#}$ \\
Sim et al, ${ }^{12}$ USA & Cross-sectional & 554 & $17-65$ years & $1.9(1.3-2.7)^{* *, \#}$ \\
Yoo and Cho, ${ }^{44}$ South Korea & Case-control & 500 & $19-91$ years & $3.32(2.26-4.85)^{\ddagger}$ \\
Coutard et al, ${ }^{20}$ France & Case-control & 186 & $70-85$ years & $1.37(0.72-2.6)^{* * *, \neq}$ \\
Jin et al, ${ }^{57}$ South Korea & Case-control & 102 & $3-24$ months & $4.93(1.87-12.98)^{\ddagger}$ \\
Chang et al, ${ }^{93}$ China & Cross-sectional & 1,218 & 6 months-14 years & $1.01(1-1.02)^{5, \neq}$ \\
Golbahar et al, ${ }^{92}$ Bahrain & Cross-sectional & 421 & $18-60$ years & $3.21(2.13-4.86)$ \\
\hline
\end{tabular}

Notes: *Fully adjusted for age, sex, race, obesity, C-reactive protein, vitamin $\mathrm{B}_{12}$, and folate; **adjusted for age, sex, and chronic kidney disease; ***adjusted for albuminemia; s̆blood lead level as predictor; \#anemia risk; ‡vitamin D-deficiency risk.

Abbreviations: OR, odds ratio; $\mathrm{Cl}$, confidence interval. 
tionship between vitamin D deficiency and anemia. ${ }^{20}$ Vitamin $\mathrm{D}(25[\mathrm{OH}] \mathrm{D})$ and hemoglobin levels were estimated. Interestingly, after adjustment for albuminemia, anemia was not significantly associated with vitamin D deficiency $(25[\mathrm{OH}] \mathrm{D}$ $<50 \mathrm{nmol} / \mathrm{L}$ ), even though anemia was significantly associated with hypoalbuminemia. The authors then concluded that malnutrition reflected by hypoalbuminemia as a surrogate could be a possible confounder in the previously described association between anemia and vitamin D deficiency. ${ }^{20}$

In a study conducted in South Korea, ${ }^{57}$ Jin et al investigated the relationship between iron status and serum vitamin $\mathrm{D}$ levels in infants. The enrolled infants were classified into iron-deficiency anemia, iron-deficient, and normal groups based on hemoglobin and ferritin levels. They were further classified into vitamin D-deficient, vitamin D-insufficient, and vitamin D-sufficient groups according to $25(\mathrm{OH}) \mathrm{D}$ levels. The major findings were the presence of vitamin $\mathrm{D}$ deficiency in a greater percentage of infants with irondeficiency anemia compared to the other groups and a significant correlation between hemoglobin and $25(\mathrm{OH}) \mathrm{D}$ levels. These results confirm the previous observation that changes in vitamin D metabolism are intricately related to iron deficiency, ${ }^{80}$ because heme-bound iron is essential in the hydroxylation process of vitamin D. ${ }^{81}$

\section{Anemia related to genetic factors (hereditary anemia)}

Common hereditary anemias, such as sickle-cell disease (SCD), $\beta$-thalassemia, and hereditary hemochromatosis, are regarded as iron-overload disorders. Expectedly, the hepcidin-ferroportin system is involved in the regulation of body iron stores in these disorders; ${ }^{85}$ hepcidin inhibits iron export from the cells by blocking the activity of ferroportin, which is the main exporter of iron from these sites. In ironoverload disorders, raised circulating iron levels result in hepatic upregulation of hepcidin expression, while elevated serum hepcidin levels diminish intestinal iron absorption and hinder iron export from tissue stores into the circulation to give protection against excessive accumulation of total body iron and its distribution into the circulation. ${ }^{86}$

This regulatory mechanism leads to "functional" iron deficiency. Apart from SCD being a chronic hemolytic disorder, its proinflammatory nature results in the elaboration of inflammatory cytokines. Both increased circulating iron levels and cytokines are potent stimulators of hepcidin synthesis, which ultimately interferes with iron availability for erythropoiesis. Nevertheless, SCD is also associated with multiple macro- and micronutrient deficiencies, such as vitamin D deficiency. Vitamin D specifically results in downregulation of inflammatory cytokines and hepcidin, which expectedly improves anemia. Therefore, its deficiency leads to the opposite effects, whose sequelae consist of depressed erythropoiesis and accentuation of the anemic state. Some authors have indeed suggested the desirability of vitamin D supplementation not only as a therapeutic measure to increase serum $25(\mathrm{OH}) \mathrm{D}$ levels in children and adults with SCD but also to improve their anemic state. ${ }^{87,88}$

\section{Anemia of chronic disease or anemia of inflammation (related to infection, rheumatoid arthritis, cancer, and CKD)}

Elsewhere in the US, other investigators conducted a crosssectional study in which they aimed to investigate the link between vitamin $\mathrm{D}$ status and anemia in an adult population, as well as the effects of race on this association. ${ }^{77}$ Their major findings were the association of low serum $25(\mathrm{OH}) \mathrm{D}(<50$ $\mathrm{nmol} / \mathrm{L}$ ) with anemia and a significant effect modification by race, such that black subjects with $25(\mathrm{OH}) \mathrm{D}$ levels $<50$ $\mathrm{nmol} / \mathrm{L}$ had increased probability of having anemia compared to their black counterparts with $25(\mathrm{OH}) \mathrm{D}$ levels $\geq 50 \mathrm{nmol} / \mathrm{L}$, unlike white subjects. The researchers thus concluded that low serum $25(\mathrm{OH}) \mathrm{D}(<50 \mathrm{nmol} / \mathrm{L})$ was significantly associated with anemia, particularly anemia of inflammation, among black subjects in a generally healthy adult cohort. ${ }^{77}$

It has been noted that vitamin D deficiency is associated with a higher prevalence of anemia of inflammation in elderly subjects $^{88}$ and is also a common finding in CKD and hemodialysis patients. ${ }^{11}$ The therapeutic effects of vitamin D supplementation in this type of anemia have been demonstrated by reports of an erythropoietin-sparing effect in vitamin D-deficient hemodialysis patients, ${ }^{53}$ as well as a correlation of vitamin D repletion with reduction in erythropoietin-dose requirements in anemic CKD patients who were not on hemodialysis. ${ }^{89} \mathrm{~A}$ mechanism for the erythropoietin-sparing effects of vitamin $D$ is suggested by recent data, which show that the vitamin reduces hepcidin levels both in vitro and in vivo. ${ }^{90}$ For instance, vitamin D supplementation in healthy subjects reduced serum levels of hepcidin by $50 \%$ compared to baseline levels within 24 hours and persisted for 72 hours, ${ }^{90}$ while its beneficial effects on increasing erythropoiesis and decreasing inflammation have been noted. ${ }^{51,91}$

In another related study, a group of researchers in Bahrain tested the hypothesis that vitamin $\mathrm{D}$ deficiency and hyperparathyroidism may be associated with anemia. ${ }^{92}$ Association of hyperparathyroidism and alterations in vitamin D levels (deficiency and insufficiency) with anemia 
was evaluated in male and female subjects. Remarkably, the prevalence of anemia was significantly associated with vitamin D deficiency independently of PTH levels in the female cohort, whereas the prevalence of anemia appeared to be significantly associated with hyperparathyroidism. This significant relationship, however, disappeared after controlling for vitamin D deficiency. The study findings suggest that in females, vitamin D deficiency is independently associated with anemia, unlike in their male counterparts. Overall, these studies $^{51,91,92}$ underscore the therapeutic effects of vitamin D supplementation in anemic patients, the effects of anemia on vitamin D metabolism, and the fact that vitamin D is a relevant micronutrient in major subtypes of anemia.

In China, Chang et al evaluated the prevalence of vitamin $\mathrm{D}$ deficiency and insufficiency and their association with hemoglobin and elevated blood lead levels in children aged between 6 months and 14 years..$^{93}$ Remarkably, the authors found a negative correlation between $25(\mathrm{OH}) \mathrm{D}$ levels and blood lead levels but could not demonstrate a significant relationship between $25(\mathrm{OH}) \mathrm{D}$ levels and hemoglobin levels. In other words, elevated blood lead levels were associated with $25(\mathrm{OH}) \mathrm{D}$ deficiency. This finding may be explained by the fact that vitamin D metabolism is closely related to iron metabolism, ${ }^{81}$ since lead is a known inhibitor of iron and thus a contributory factor in iron deficiency.

Finally, Yoo and Cho conducted a case-control study in South Korea to compare serum 25(OH)D levels based on the presence and subtypes of anemia. ${ }^{94}$ They not only observed a higher prevalence of $25(\mathrm{OH}) \mathrm{D}$ deficiency in the anemic group than in the nonanemic group but also recorded a significantly higher prevalence of severe $25(\mathrm{OH}) \mathrm{D}$ deficiency in the former group than in the latter group, with an odds ratio of 3.32 (95\% confidence interval 2.26-4.85). Interestingly, the prevalence of $25(\mathrm{OH}) \mathrm{D}$ deficiency was not different among the subtypes of anemia. This study again showed that vitamin D deficiency is associated with anemia, irrespective of the subtype, and underscored the need for estimating serum 25(OH)D levels and giving appropriate vitamin $\mathrm{D}$ supplementation in anemic patients. ${ }^{94}$ However, it tends to support the view that vitamin D deficiency may not be part of the cause, but rather an effect of the anemic state.

\section{Conclusion}

Although the causal association of vitamin D deficiency with anemia risk (especially iron-deficiency anemia) remains debatable, the noncalcemic actions of the vitamin and its analogs hold prospects for several novel clinical applications. However, there is unanimity in many reports suggesting that vitamin D deficiency is directly associated with anemia of chronic disease or inflammation; therefore, the therapeutic effects of vitamin D supplementation in CKD are well established. By suppressing proinflammatory cytokines and directly inhibiting hepcidin expression, vitamin D may indeed be effective in mobilizing iron stores and enhancing erythropoiesis and hemoglobin synthesis. ${ }^{14}$

The alternative hypothesis that vitamin D deficiency may be a concurrent event or an effect of anemia has also opened a new vista in therapeutic approach for patients with anemia. Despite the advances in unraveling the role of vitamin D in iron homeostasis, further research is still required to validate causality in the relationship between vitamin D deficiency and anemia, as well as to determine its optimal dosing, the ideal recipients for therapeutic intervention, and the preferred analogs to administer.

\section{Disclosure}

The author reports no conflicts of interest in this work.

\section{References}

1. Lips P. Vitamin D physiology. Prog Biophys Mol Biol. 2006;92:4-8.

2. Zittermann A. Vitamin D in preventive medicine: are we ignoring the evidence? Br J Nutr. 2003;89:552-572.

3. Shroff R, Knott C, Rees L. The virtues of vitamin D: but how much is too much? Pediatr Nephrol. 2010;25:1607-1620.

4. Zittermann A. Vitamin D and disease prevention with special reference to cardiovascular disease. Prog Biophys Mol Biol. 2006;92:39-48.

5. Bikle D. Nonclassic actions of vitamin D. J Clin Endocrinol Metab. 2009;94:26-34.

6. DeLuca HF. Overview of general physiologic features and functions of vitamin D. Am J Clin Nutr. 2004;80:S1689-S1696.

7. Penna G, Roncari A, Amuchastegui S, et al. Expression of the inhibitory receptor ILT3 on dendritic cells is dispensable for induction of CD4+Foxp3+ regulatory T cells by 1,25-dihydroxyvitamin D3. Blood. 2005; 106:3490-3497.

8. Li YC. Vitamin D regulation of the renin-angiotensin system. J Cell Biochem. 2003;88:327-331.

9. Chiu KC, Chu A, Go VL, Saad MF. Hypovitaminosis D is associated with insulin resistance and $\beta$ cell dysfunction. Am J Clin Nutr. 2004; 79:820-825.

10. Albitar S, Genin R, Fen-Chong M, Serveaux MO, Schohn D, Chuet C. High-dose alfacalcidol improves anaemia in patients on haemodialysis. Nephrol Dial Transplant. 1997;12:514-518.

11. Saab G, Young DO, Gincherman Y, Giles K, Norwood K, Coyne DW. Prevalence of vitamin D deficiency and the safety and effectiveness of monthly ergocalciferol in hemodialysis patients. Nephron Clin Pract. 2007; 105:c132-c138.

12. Sim JJ, Lac PT, Liu IA, et al. Vitamin D deficiency and anemia: a crosssectional study. Ann Hematol. 2010;89:447-452.

13. Norman AW. Minireview - vitamin D receptor: new assignments for an already busy receptor. Endocrinology. 2006;147:5542-5548.

14. Smith EM, Tangpricha V. Vitamin D and anemia: insights into an emerging association. Curr Opin Endocrinol Diabetes Obes. 2015;22: 432-438.

15. Liu T, Zhong S, Liu L, et al. Vitamin D deficiency and the risk of anemia: a meta-analysis of observational studies. Ren Fail. 2015;37:929-934.

16. Atkinson MA, Melamed ML, Kumar J, et al. Vitamin D, race, and risk for anemia in children. J Pediatr. 2014;164:153-158. 
17. Zittermann A, Kuhn J, Dreier J, et al. Association of 25-hydroxyvitamin $\mathrm{D}$ with anemia risk in patients scheduled for cardiac surgery. Int J Lab Hematol. 2014;36:29-36.

18. Ernst JB, Becker T, Kuhn J, Gummert JF, Zittermann A. Independent association of circulating vitamin $\mathrm{D}$ metabolites with anemia risk in patients scheduled for cardiac surgery. PLoS One. 2015;10:e0124751.

19. Zittermann A, Jungvogel A, Prokop S, et al. Vitamin D deficiency is an independent predictor of anemia in end-stage heart failure. Clin Res Cardiol. 2011;100:781-788.

20. Coutard A, Garlantézec R, Estivin S, Andro M, Gentric A. Association of vitamin $\mathrm{D}$ deficiency and anemia in a hospitalized geriatric population: denutrition as a confounding factor. Ann Hematol. 2013;92:615-619.

21. Weiss G, Goodnough LT. Anemia of chronic disease. $N$ Engl J Med. 2005;352:1011-1023.

22. Yoon JW, Kim SW, Yoo EG, Kim MK. Prevalence and risk factors for vitamin D deficiency in children with iron deficiency anemia. Korean J Pediatr. 2012;55:206-211.

23. Lee JA, Hwang JS, Hwang IT, Kim DH, Seo JH, Lim JS. Low vitamin D levels are associated with both iron deficiency and anemia in children and adolescents. Pediatr Hematol Oncol. 2015;32:99-108.

24. Suh YJ, Lee JE, Lee DH, et al. Prevalence and relationships of iron deficiency anemia with blood cadmium and vitamin D levels in Korean women. J Korean Med Sci. 2016;31:25-32.

25. Kadowaki S, Norman AW. Demonstration that the vitamin D metabolite $1,25(\mathrm{OH})_{2}$-vitamin D3 and not $24 \mathrm{R}, 25(\mathrm{OH})_{2}$-vitamin D3 is essential for normal insulin secretion in the perfused rat pancreas. Diabetes. $1985 ; 34: 315-320$

26. Lee S, Clark SA, Gill RK, Christakos S. 1,25-Dihydroxyvitamin D3 and pancreatic beta-cell function: vitamin D receptors, gene expression, and insulin secretion. Endocrinology. 1994;134:1602-1610.

27. Clark SA, StumpfWE, Sar M, DeLuca HF, Tanaka Y. Target cells for 1,25 dihydroxyvitamin D3 in the pancreas. Cell Tissue Res. 1980;209:515-520.

28. Sooy K, Schermerhorn T, Noda M, et al. Calbindin- $\mathrm{D}_{28 \mathrm{k}}$ controls $\left(\mathrm{Ca}^{2+}\right)$ ${ }_{i}$ and insulin release: evidence obtained from calbindin- $D_{28 \mathrm{k}}$ knockout mice and $\beta$ cell lines. J Biol Chem. 1999;274:34343-34349.

29. Rabinovitch A, Suarez-Pinzon WL, Sooy K, Strynadka K, Christakos S. Expression of calbindin- $\mathrm{D}_{28 \mathrm{k}}$ in a pancreatic islet $\beta$-cell line protects against cytokine-induced apoptosis and necrosis. Endocrinology. 2001;142:3649-3655.

30. Chiu KC, Chu A, Go VL, Saad MF. Hypovitaminosis D is associated with insulin resistance and $\beta$-cell dysfunction. Am J Clin Nutr. 2004; 79:820-825.

31. Scragg R, Sowers M, Bell C. Serum 25-hydroxyvitamin D, diabetes, and ethnicity in the Third National Health and Nutrition Examination Survey. Diabetes Care. 2004;27:2813-2818.

32. Scragg R, Holdaway I, Singh V, Metcalf P, Baker J, Dryson E. Serum 25-hydroxyvitamin D3 levels decreased in impaired glucose tolerance and diabetes mellitus. Diabetes Res Clin Pract. 1995;27:181-188.

33. Inomata S, Kadowaki S, Yamatani T, Fukase M, Fujita T. Effect of 1 alpha $(\mathrm{OH})$-vitamin $\mathrm{D} 3$ on insulin secretion in diabetes mellitus. Bone Miner. 1986;1:187-192.

34. Pittas AG, Harris SS, Stark PC, Dawson-Hughes B. The effects of calcium and vitamin D supplementation on blood glucose and markers of inflammation in nondiabetic adults. Diabetes Care. 2007;30:980-986.

35. Al-Shoumer KA, Al-Essa TM. Is there a relationship between vitamin $\mathrm{D}$ with insulin resistance and diabetes mellitus? World J Diabetes. 2015;6:1057-1064.

36. Johnson JA, Grande JP, Roche PC, Kumar R. Immuno-histochemical localization of the $1,25(\mathrm{OH}) 2 \mathrm{D} 3$ receptor and calbindin $\mathrm{D} 28 \mathrm{k}$ in human and rat pancreas. Am J Physiol. 1994;267:E356-E360.

37. Bland R, Markovic D, Hills CE, et al. Expression of 25-hydroxyvitamin D3-1 $\alpha$-hydroxylase in pancreatic islets. J Steroid Biochem Mol Biol. 2004;89-90:121-125.

38. Maestro B, Molero S, Bajo S, Dávila N, Calle C. Transcriptional activation of the human insulin receptor gene by 1,25-dihydroxyvitamin $\mathrm{D}_{3}$. Cell Biochem Funct. 2002;20:227-232.
39. Simpson RU, Thomas GA, Arnold AJ. Identification of 1,25-dihydroxyvitamin D3 receptors and activities in muscle. J Biol Chem. 1985;260:8882-889.

40. Maestro B, Campión J, Dávila N, Calle C. Stimulation by 1,25-dihydroxyvitamin D3 of insulin receptor expression and insulin responsiveness for glucose transport in U-937 human promonocytic cells. Endocr J. 2000;47:383-339

41. Hu FB, Meigs JB, Li TY, Rifai N, Manson JE. Inflammatory markers and risk of developing type 2 diabetes in women. Diabetes. 2004; 53:693-700.

42. Duncan BB, Schmidt MI, Pankow JS, et al. Low-grade systemic inflammation and the development of type 2 diabetes: the atherosclerosis risk in communities study. Diabetes. 2003;52:1799-1805.

43. Riachy R, Vandewalle B, Conte JK, et al. 1,25-Dihydroxyvitamin D3 protects RINm5F and human islet cells against cytokine-induced apoptosis: implication of the anti-apoptotic protein A20. Endocrinology. 2002;143:4809-4819.

44. Hess D, Li L, Martin M, et al. Bone marrow-derived stem cells initiate pancreatic regeneration. Nat Biotechnol. 2003;21:763-770.

45. Wlazlo N, van Greevenbroek MM, Ferreira I, et al. Iron metabolism is associated with adipocyte insulin resistance and plasma adiponectin: the Cohort on Diabetes and Atherosclerosis Maastricht (CODAM) study. Diabetes Care. 2013;36:309-315.

46. Fernández-Real JM, McClain D, Manco M. Mechanisms linking glucose homeostasis and iron metabolism toward the onset and progression of type 2 diabetes. Diabetes Care. 2015;38:2169-2176.

47. Dongiovanni P, Ruscica M, Rametta R, Recalcati S, Steffani L, Gatti S. Dietary iron overload induces visceral adipose tissue insulin resistance. Am J Pathol. 2013;182:2254-2263.

48. Ganz T. Hepcidin and iron regulation, 10 years later. Blood. 2011;117: 4425-4433.

49. Nemeth E, Ganz T. Anemia of inflammation. Hematol Oncol Clin North Am. 2014;28:671-681.

50. Alon DB, Chaimovitz C, Dvilansky A, et al. Novel role of 1,25(OH)2D3 in induction of erythroid progenitor cell proliferation. Exp Hematol. 2002;30:403-409.

51. Aucella F, Scalzulli RP, Gatta G, Vigilante M, Carella AM, Stallone C. Calcitriol increases burst-forming unit-erythroid proliferation in chronic renal failure: a synergistic effect with r-HuEpo. Nephron Clin Pract. 2003;95:c121-c127.

52. Kiss Z, Ambrus C, Almasi C, et al. Serum 25(OH)-cholecalciferol concentration is associated with hemoglobin level and erythropoietin resistance in patients on maintenance hemodialysis. Nephron Clin Pract. 2011;117:c373-c378.

53. Kumar VA, Kujubu DA, Sim JJ, Rasgon SA, Yang PS. Vitamin D supplementation and recombinant human erythropoietin utilization in vitamin D-deficient hemodialysis patients. J Nephrol. 2011;24: 98-105.

54. Razzaque MS. The FGF23-Klotho axis: endocrine regulation of phosphate homeostasis. Nature. 2009;5:611-619.

55. Scialla JJ, Wolf M. Roles of phosphate and fibroblast growth factor 23 in cardiovascular disease. Nat Rev Nephrol. 2014;10:268-278.

56. Icardi A, Paoletti E, De Nicola L, Mazzaferro S, Russo R, Cozzolino M. Renal anaemia and EPO hyporesponsiveness associated with vitamin D deficiency: the potential role of inflammation. Nephrol Dial Transplant. 2013;28:1672-1679.

57. Jin HJ, Lee JH, Kim MK. The prevalence of vitamin D deficiency in iron-deficient and normal children under the age of 24 months. Blood Res. 2013;48:40-45.

58. Patel NM, Gutierrez OM, Andress DL, Coyne DW, Levin A, Wolf M. Vitamin D deficiency and anemia in early chronic kidney disease. Kidney Int. 2010;77:715-720.

59. Goicoechea M, Vazquez MI, Ruiz MA, Gomez-Campdera F, PerezGarcía R, Valderrábano F. Intravenous calcitriol improves anaemia and reduces the need for erythropoietin in haemodialysis patients. Nephron. 1998;78:23-27. 
60. Lin CL, Hung CC, Yang CT, Huang CC. Improved anemia and reduced erythropoietin need by medical or surgical intervention of secondary hyperparathyroidism in hemodialysis patients. Ren Fail. 2004;26:289-295.

61. Riccio E, Sabbatini M, Bruzzese D, et al. Effect of paricalcitol vs calcitriol on hemoglobin levels in chronic kidney disease patients: a randomized trial. PLoS One. 2015;10:e0118174.

62. Sooragonda B, Bhadada SK, Shah VN, Malhotra P, Ahluwalia J, Sachdeva N. Effect of vitamin D replacement on hemoglobin concentration in subjects with concurrent iron-deficiency anemia and vitamin D deficiency: a randomized, single-blinded, placebo-controlled trial. Acta Haematol. 2015;133:31-35.

63. Provvedini DM, Tsoukas CD, Deftos LJ, Manolagas SC. 1,25-Dihydroxyvitamin D3 receptors in human leukocytes. Science. 1983;221:1181-1183.

64. Rigby WF, Stacy T, Fanger MW. Inhibition of T lymphocyte mitogenesis by 1,25-dihydroxyvitamin D3 (calcitriol). J Clin Invest. 1984; 74:1451-1455.

65. Adams JS, Sharma OP, Gacad MA, Singer FR. Metabolism of 25-hydroxyvitamin D3 by cultured pulmonary alveolar macrophages in sarcoidosis. J Clin Invest. 1983;72:1856-1860.

66. Hewison M, Burke F, Evans KN, et al. Extra-renal 25-hydroxyvitamin D3-1 $\alpha$-hydroxylase in human health and disease. J Steroid Biochem Mol Biol. 2007;103:316-321.

67. Chen S, Sims GP, Chen XX, Gu YY, Chen S, Lipsky PE. Modulatory effects of 1,25-dihydroxyvitamin D3 on human B cell differentiation. J Immunol. 2007;179:1634-1647.

68. Lemire JM, Archer DC, Beck L, Spiegelberg HL. Immunosuppressive actions of 1,25-dihydroxyvitamin D3: preferential inhibition of Th1 functions. J Nutr. 1995;125:1704S-1708S.

69. Gombart AF, Borregaard N, Koeffler HP. Human cathelicidin antimicrobial peptide (CAMP) gene is a direct target of the vitamin D receptor and is strongly up-regulated in myeloid cells by 1,25-dihydroxyvitamin D3. FASEB J. 2005;19:1067-1077.

70. Wang TT, Nestel FP, Bourdeau V, et al. Cutting edge: 1,25-dihydroxyvitamin D3 is a direct inducer of antimicrobial peptide gene expression. J Immunol. 2004;173:2909-2912.

71. Almerighi C, Sinistro A, Cavazza A, Ciaprini C, Rocchi G, Bergamini A. 1 $\alpha, 25$-Dihydroxyvitamin D3 inhibits CD40L-induced pro-inflammatory and immunomodulatory activity in human monocytes. Cytokine 2009;45:190-197.

72. Nemeth E. Targeting the hepcidin-ferroportin axis in the diagnosis and treatment of anemias. Adv Hematol. 2010;2010:750643

73. Roy CN, Andrews NC. Anemia of inflammation: the hepcidin link. Curr Opin Hematol. 2005;12:107-111.

74. Carvalho $\mathrm{C}$, Isakova $\mathrm{T}$, Collerone $\mathrm{G}$, et al. Hepcidin and disordered mineral metabolism in chronic kidney disease. Clin Nephrol. 2011;76:90-98.

75. Blazsek I, Farabos C, Quittet P, et al. Bone marrow stromal cell defects and $1 \alpha, 25$-dihydroxyvitamin D3 deficiency underlying human myeloid leukemias. Cancer Detect Prev. 1996;20:31-42.

76. Alon DB, Chaimovitz C, Dvilansky A, et al. Novel role of $1,25(\mathrm{OH})_{2} \mathrm{D}_{3}$ in induction of erythroid progenitor cell proliferation. Exp Hematol. 2002;30:403-409.
77. Smith EM, Alvarez JA, Martin GS, Zughaier SM, Ziegler TR, Tangpricha V. Vitamin D deficiency is associated with anaemia among African Americans in a US cohort. Br J Nutr. 2015;113: 1732-1740.

78. Ganji V, Zhang X, Tangpricha V. Serum 25-hydroxyvitamin D concentrations and prevalence estimates of hypovitaminosis D in the U.S. population based on assay-adjusted data. J Nutr. 2012;142:498-507.

79. Zakai NA, McClure LA, Prineas R, et al. Correlates of anemia in American blacks and whites: the REGARDS Renal Ancillary study. Am J Epidemiol. 2009;169:355-364.

80. Azizi-Soleiman F, Vafa M, Abiri B, Safavi M. Effects of iron on vitamin D metabolism: a systematic review. Int J Prev Med. 2016;7:126.

81. Jones G, Prosser DE, Kaufmann M. Cytochrome P450-mediated metabolism of vitamin D. J Lipid Res. 2014;55:13-31.

82. Toxqui L, Vaquero MP. Chronic iron deficiency as an emerging risk factor for osteoporosis: a hypothesis. Nutrients. 2015;7:2324-2344.

83. Díaz-Castro J, López-Frías MR, Campos MS, et al. Severe nutritional iron-deficiency anaemia has a negative effect on some bone turnover biomarkers in rats. Eur J Nutr. 2012;51:241-247.

84. Wright I, Blanco-Rojo R, Fernández MC, et al. Bone remodeling is reduced by recovery from iron-deficiency anaemia in premenopausal women. J Physiol Biochem. 2013;69:889-896.

85. Blanco-Rojo R, Pérez-Granados AM, Toxqui L, Zazo P, de la Piedra C, Vaquero MP. Relationship between vitamin D deficiency, bone remodeling and iron status in iron-deficient young women consuming an iron-fortified food. Eur J Nutr. 2013;52:695-703.

86. Ganz T, Nemeth E. The hepcidin-ferroportin system as a therapeutic target in anemias and iron overload disorders. Hematology Am Soc Hematol Educ Program. 2011;2011:538-542.

87. Soe HH, Kyaw A, Adinegara B, et al. Vitamin D supplementation for sickle cell disease. Cochrane Database Syst Rev. 2017;1:CD010858.

88. Perlstein TS, Pande R, Berliner N, Vanasse GJ. Prevalence of 25-hydroxyvitamin D deficiency in subgroups of elderly persons with anemia: association with anemia of inflammation. Blood. 2011;117: 2800-2806.

89. Lac PT, Choi K, Lui IA, Sim JJ. The effects of changing vitamin D levels on anemia in chronic kidney disease patients: a retrospective cohort review. Clin Nephrol. 2010;74:25-32.

90. Sun CC, Vaja V, Babitt JL, Herbert YL. Targeting the hepcidinferroportin axis to develop new treatment strategies for anemia of chronic disease and anemia of inflammation. Am J Hematol. 2012;87: 392-400.

91. Panichi V, De Pietro S, Andreini B, Palla R. Calcitriol modulates in vivo and in vitro cytokine production: a role for intracellular calcium. Kidney Int. 1998;54:1463-1469.

92. Golbahar J, Altayab D, Carreon E, Darwish A. Association of vitamin D deficiency and hyperparathyroidism with anemia: a cross-sectional study. J Blood Med. 2013;4:123-128.

93. Chang L, Liu X, Shi H, Dai W, Wang H, Jiang Y. Association of 25-hydroxyvitamin $\mathrm{D}$ with $\mathrm{Hb}$ and lead in children: a Chinese population-based study. Public Health Nutr. 2013;17:827-832.

94. Yoo EH, Cho HJ. Prevalence of 25-hydroxyvitamin D deficiency in Korean patients with anemia. J Clin Lab Anal. 2015;29:129-134.
Pediatric Health, Medicine and Therapeutics

\section{Publish your work in this journal}

Pediatric Health, Medicine and Therapeutics is an international, peerreviewed, open access journal publishing original research, reports, editorials, reviews and commentaries. All aspects of health maintenance, preventative measures and disease treatment interventions are addressed within the journal. Practitioners from all disciplines are invited to submit
Dovepress

their work as well as healthcare researchers and patient support groups. The manuscript management system is completely online and includes a very quick and fair peer-review system. Visit http://www.dovepress.com/ testimonials.php to read real quotes from published authors. 